\title{
El lado menos dulce de la diabetes. Revisión pictográfica de las alteraciones más frecuentes en el pie diabético
}

\section{The not-so-sweet Side of Diabetes. Pictorial Review of the Most Frequent Diabetic Foot Disorders}

\author{
Gabriela Rodríguez ${ }^{1}$ Andrés Kunstmann ${ }^{1}$ Pablo Jara ${ }^{1}$ Cristóbal Gaete ${ }^{1}$ Giancarlo Schiappacasse ${ }^{2}$ \\ ${ }^{1}$ Universidad de Santiago de Chile, Región Metropolitana, Chile \\ 2 Departamento de Diagnóstico por Imagen, Hospital Militar de \\ Address for correspondence Giancarlo Schiappacasse, Av. Alcalde \\ Santiago, Región Metropolitana, Chile \\ Fernando Castillo Velasco 9100, La Reina, Región Metropolitana, Chile \\ (e-mail: gschiappacasse@gmail.com).
}

Rev Argent Radiol 2021;85:68-74.

\section{Resumen \\ Palabras clave \\ - pie \\ - artropatía neuropática \\ - osteomielitis \\ - resonancia magnética \\ - radiografía}

La prevalencia global de diabetes mellitus (DM) aumenta cada año y, con ella, sus complicaciones. La afección del pie relacionada con DM se ha convertido en una de las principales causas de morbilidad y discapacidad. Los hallazgos más frecuentes son las alteraciones cutáneas y musculares, la arterioesclerosis y el edema óseo. Las complicaciones son la osteomielitis y la neuroartropatía, siendo causas importantes de amputación. El estudio imagenológico se inicia con radiografía (Rx), que permite descartar anomalías óseas y articulares, presencia de cuerpos extraños o alteraciones del tejido blando. Después de la Rx, la resonancia magnética (RM) es la modalidad de elección para la evaluación de la osteomielitis e infección de tejidos blandos del pie. Aunque esas afecciones comparten algunas características clínicas y de imagen con otros trastornos, el conocimiento de sus hallazgos distintivos permite al radiólogo contribuir al diagnóstico oportuno y correcto, con el fin de proporcionar al clínico información adecuada.

The global prevalence of Diabetes Mellitus (DM) tends to increase over the years, along with its complications. Diabetes related foot disease has become one of the leading causes of morbidity and disability. The most frequent findings are skin and muscle disorders, arteriosclerosis and bone marrow edema. Complications are osteomyelitis and neuroarthropathy, being important causes of amputation. The imaging study begins with radiography, which allows to rule out bone and joint abnormalities, presence of foreign bodies or soft tissue alterations. After radiography, magnetic resonance imaging (MRI) is the chosen modality to study osteomyelitis and soft tissue infection of the foot. Although these conditions share some clinical and imaging characteristics with other disorders, to know the distinctive findings allows the radiologist to contribute to get a timely and correct diagnosis, providing as well an appropriate information to the clinician. received

March 21, 2020

accepted

October 2, 2020

published online

February 4, 2021
DOI https://doi.org/

10.1055/s-0040-1721346.

ISSN 1852-9992. @ 2021. Asociación Civil Sociedad Argentina de Radiología and
Federacion Argentina de Asociaciones de Radiología, Diagnóstico
por Imágenes y Terapia Radiante. All rights reserved.
This is an open access article published by Thieme under the terms of the
Creative Commons Attribution-NonDerivative-NonCommercial-License,
permitting copying and reproduction so long as the original work is given
appropriate credit. Contents may not be used for commercial purposes, or
adapted, remixed, transformed or built upon. (https://creativecommons.org/
licenses/by-nc-nd/4.0/)
Thieme Revinter Publicações Ltda., Rua do Matoso 170, Rio de
Janeiro, RJ, CEP 20270-135, Brazil 


\section{Introducción}

La prevalencia global de diabetes mellitus (DM) aumenta cada año, siendo considerada actualmente como una causa endémica de morbi-mortalidad en países desarrollados. ${ }^{1}$ Se calcula que alrededor de 425 millones de personas en todo el mundo, o el 8,8\% de los adultos de 20 a 79 años, tienen DM. ${ }^{2}$

La neuropatía, nefropatía y retinopatía diabética son secuelas ampliamente reconocidas y, junto al aumento de la prevalencia de $\mathrm{DM}$, se ha visto un incremento de las complicaciones músculo-esqueléticas. ${ }^{3}$ Especialmente la afección del pie corresponde a una de las principales causas de morbilidad y discapacidad, con una prevalencia de $15-20 \%{ }^{1}$

Entre los factores de riesgo para el desarrollo de úlceras en el pie, se incluyen la enfermedad microvascular con neuropatía secundaria y redistribución de la grasa plantar que, combinados con traumas desapercibidos o infecciones agregadas, pueden conducir a la amputación del pie. ${ }^{4}$

El estudio imagenológico se inicia con la radiografía (Rx), que ayuda a descartar anomalías óseas, de tejido blando y cuerpos extraños. Sin embargo, ha demostrado sensibilidad y especificidad limitada en el diagnóstico de osteomielitis. ${ }^{1}$ La tomografía computada (TC) permite caracterizar mejor los hallazgos de la Rx. Después de la $\mathrm{Rx}$, la resonancia magnética (RM) es la modalidad de elección para la evaluación de la osteomielitis e infección de tejidos blandos del pie, por su alta sensibilidad y especificidad. ${ }^{4}$

Considerando el aumento de la prevalencia de DM en la población general, es de suma importancia conocer los hallazgos imagenológicos esperables para esa condición y sus complicaciones.

\section{Alteraciones Cutáneas}

En el plano cutáneo, son frecuentes las induraciones, lesiones y úlceras en las zonas de apoyo, pudiendo asociarse a bursitis o colecciones de líquido en el tejido subcutáneo. Las úlceras se manifiestan en imágenes de RM y TC como un defecto cutáneo con márgenes bien delimitados y realce de los bordes con el medio de contraste, generando una ruta de infección que puede llevar a la osteomielitis (-Fig. 1). ${ }^{4-6}$

\section{Alteraciones Musculares}

Los trastornos musculares en pacientes portadores de diabetes son mejor caracterizados mediante RM e incluyen principalmente la isquemia muscular, la miositis y la denervación. La isquemia muscular diabética, también conocida como infarto muscular o mionecrosis diabética, ocurre generalmente en pacientes diabéticos de larga data, con mal control metabólico. Se caracteriza por un inicio clínico abrupto, con dolor severo, aumento de volumen en días o semanas, en ausencia de leucocitosis y fiebre. La RM es la técnica de elección, donde se observa aumento de volumen y edema muscular y fascial en secuencias sensibles a líquido (secuencias potenciadas en T2). Tras la inyección de contraste,

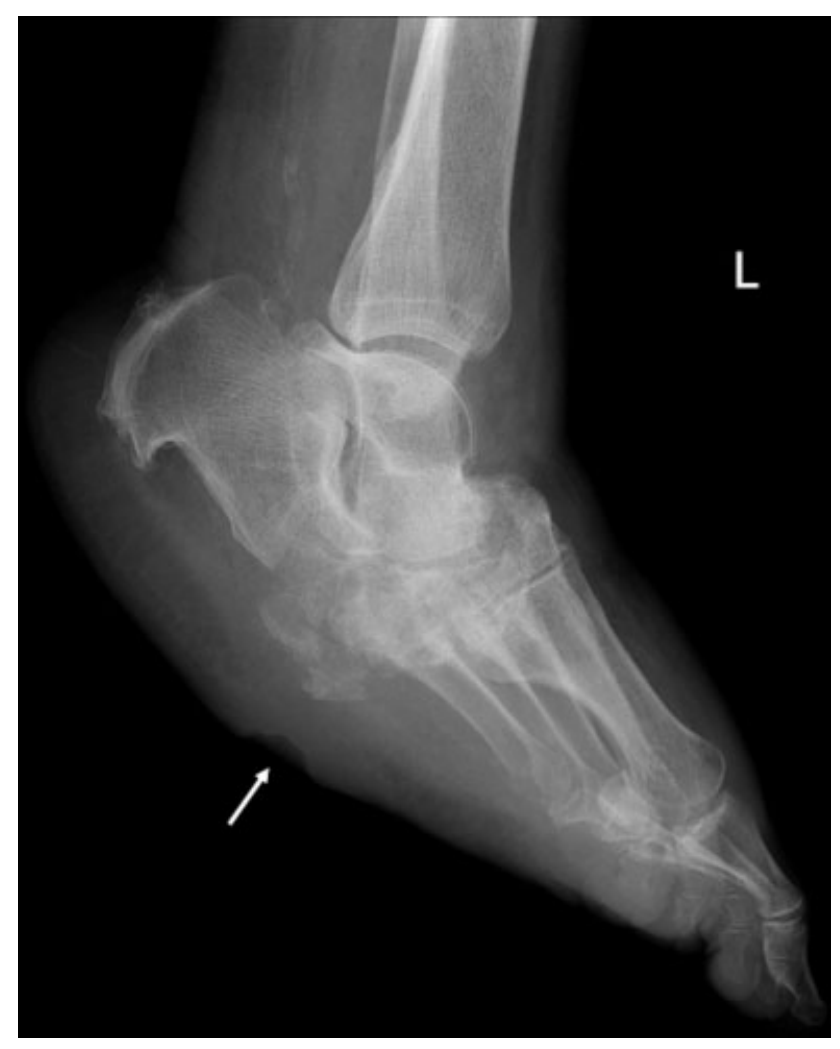

Fig. 1 Rx de pie izquierdo (proyección lateral). Úlcera cutánea plantar (flecha) y cambios secundarios a neuroartropatía avanzada, caracterizados por fragmentación ósea a nivel del tarso, desorganización articular tarso-metatarsiana y pérdida del arco plantar con deformidad "en mecedora."

se puede observar realce muscular, frecuentemente con áreas centrales con hipo-realce. ${ }^{3,7}$

Debido a la disfunción inmune subyacente, los pacientes son vulnerables a miositis infecciosa, la que habitualmente resulta de siembra por vía hematógena al músculo. Se puede confundir con la isquemia muscular diabética, diferenciándose de ella por la formación de abscesos intramusculares, con pared fina, realce anular y restricción a la difusión (en RM). También apoya la miositis infecciosa la presencia de fiebre, leucocitosis con desviación a izquierda, elevación de marcadores inflamatorios y bacteriemia., ${ }^{3,8}$

La denervación muscular corresponde a uno de los hallazgos más frecuentemente observados en esa patología. Tiene una etiología multifactorial, con la neuropatía periférica como una de sus principales causas. La denervación muscular subaguda se caracteriza por hiperintensidad de señal en secuencias ponderadas en T2, con mantención de su morfología e intensidad de señal en secuencias ponderadas en T1. En la fase crónica, se evidencia infiltración grasa, que es más visible en secuencias ponderadas en T1. Se puede observar predominantemente en la musculatura intrínseca del pie (-Fig. 2). ${ }^{3,9}$

\section{Arterioesclerosis}

Ocurre predominantemente en las arterias distales de extremidades inferiores que incluyen arterias tibiales 

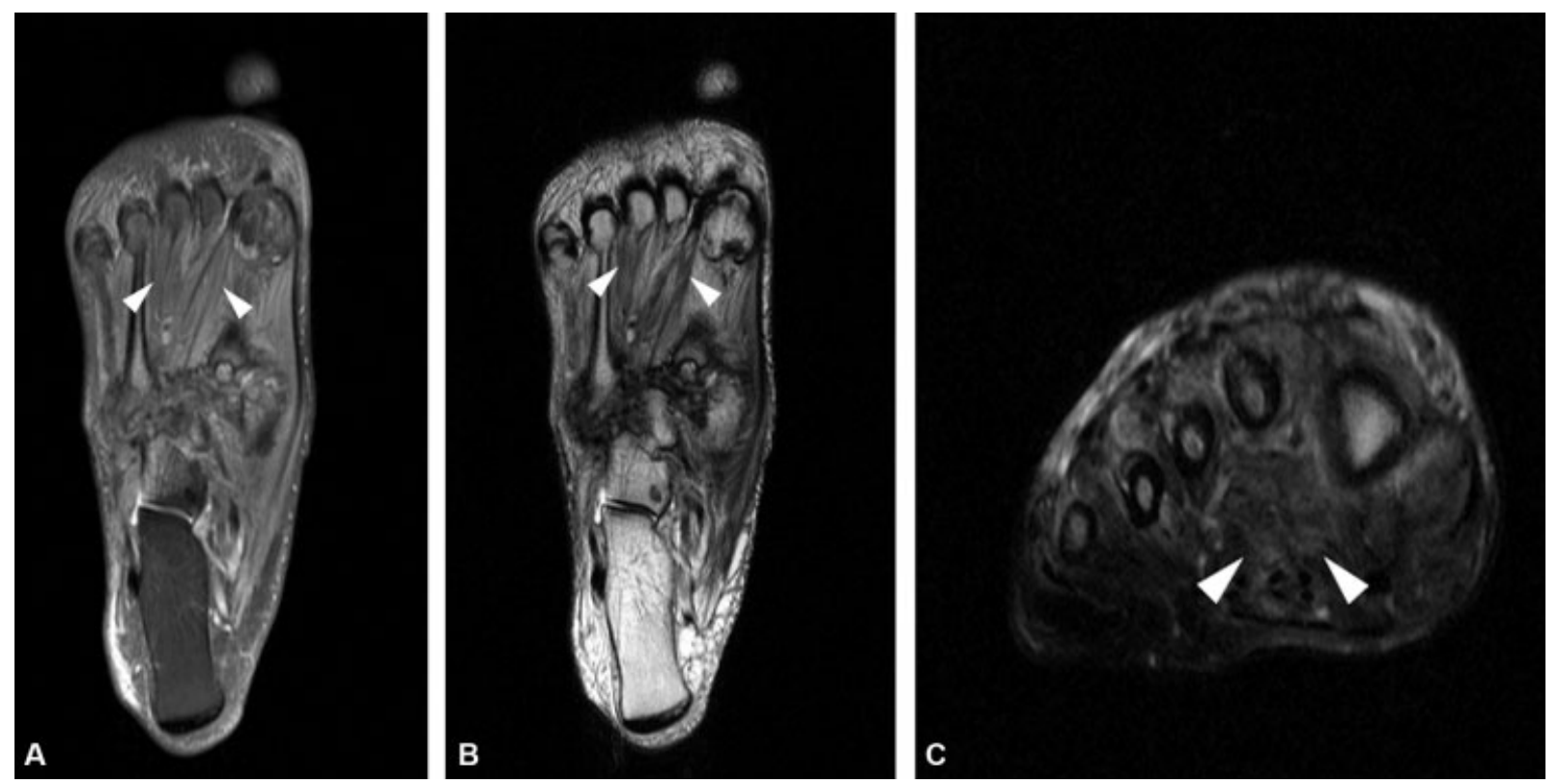

Fig. 2 RM de pie. Secuencias (A) DP fat-sat axial, (B) ponderada en T2 axial y (C) ponderada en T2 fat-sat coronal. Atrofia e infiltración grasa de los planos musculares del mediopié asociado a leve edema regional (puntas de flecha).
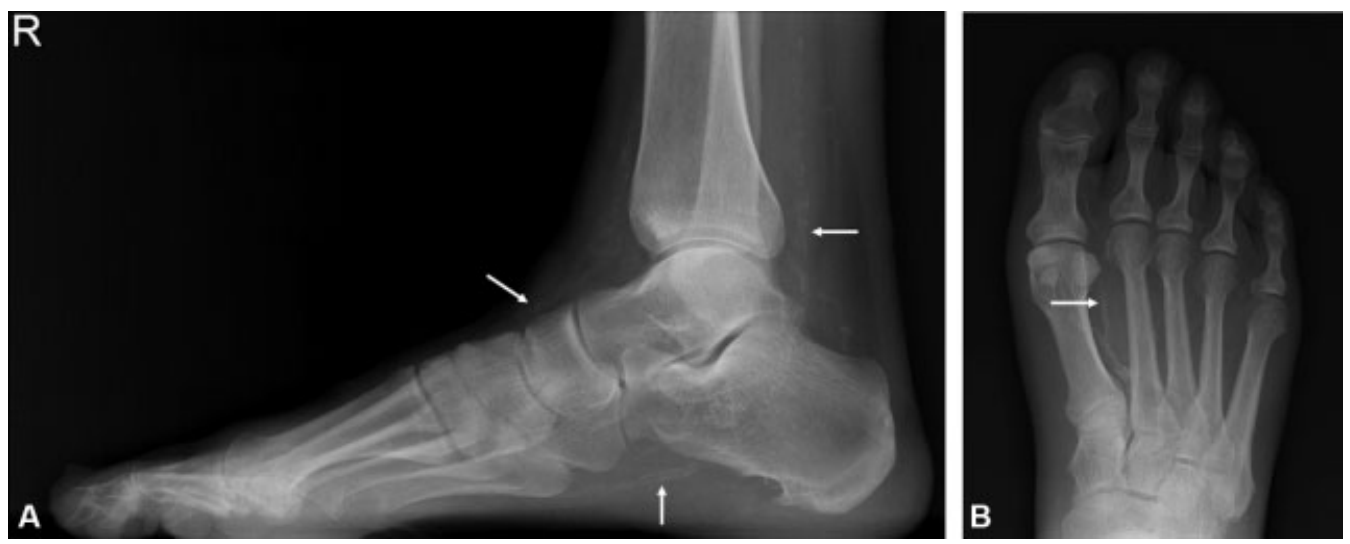

Fig. 3 Rx de pie derecho, proyecciones (A) lateral y (B) anteroposterior. Calcificaciones vasculares (flechas) de arterias pedia, plantar, intermetatarsianas e interdigitales (arterioesclerosis avanzada).

anteriores y posteriores, peroneas distales, pedias y arcos plantares, visualizándose en todas las modalidades de imágenes como calcificaciones lineales en sus trayectos (-Fig. 3). Eso puede determinar áreas de isquemia que pueden llevar a la desvitalización del tejido, observándose en TC y RM como áreas focales de tejidos blandos que no realzan tras la administración de medio de contraste, con un límite bien definido con el tejido adyacente que realza con el contraste intravenoso. Ante esos hallazgos, se debe considerar también la posibilidad de absceso, valiéndose de elementos como la presencia de burbujas de aire para su diferenciación. La isquemia crónica también puede dar lugar a infartos óseos, que se reconocen en RM como alteraciones de señal intramedulares de contornos serpiginosos relativamente bien definidos que se rodean de un halo hipointenso en secuencias ponderadas en $\mathrm{T} 1$ e hiperintenso en secuencias ponderadas en T2. ${ }^{1,3,5,6}$

\section{Edema Óseo}

Se presenta predominantemente en el mediopié y compromete al conjunto de estructuras óseas y partes blandas adyacentes, no limitándose a un solo hueso. Se visualiza en RM como áreas de alta señal en secuencias ponderadas en T2 y STIR, con leve realce tras la administración de contraste en secuencia ponderada T1 fat-sat, de predominio subcondral en etapas iniciales. (-Fig. 4). ${ }^{1,4,5,10}$

\section{Complicaciones}

\section{Neuroartropatía de Charcot}

Se trata de un trastorno que combina mecanismos neurogénicos y vasculares, que resultan en pérdida de sensibilidad y de la respuesta microvascular, asociado a discapacidad muscular. Puede afectar a cualquier articulación. Sin embargo, en la población diabética, el 

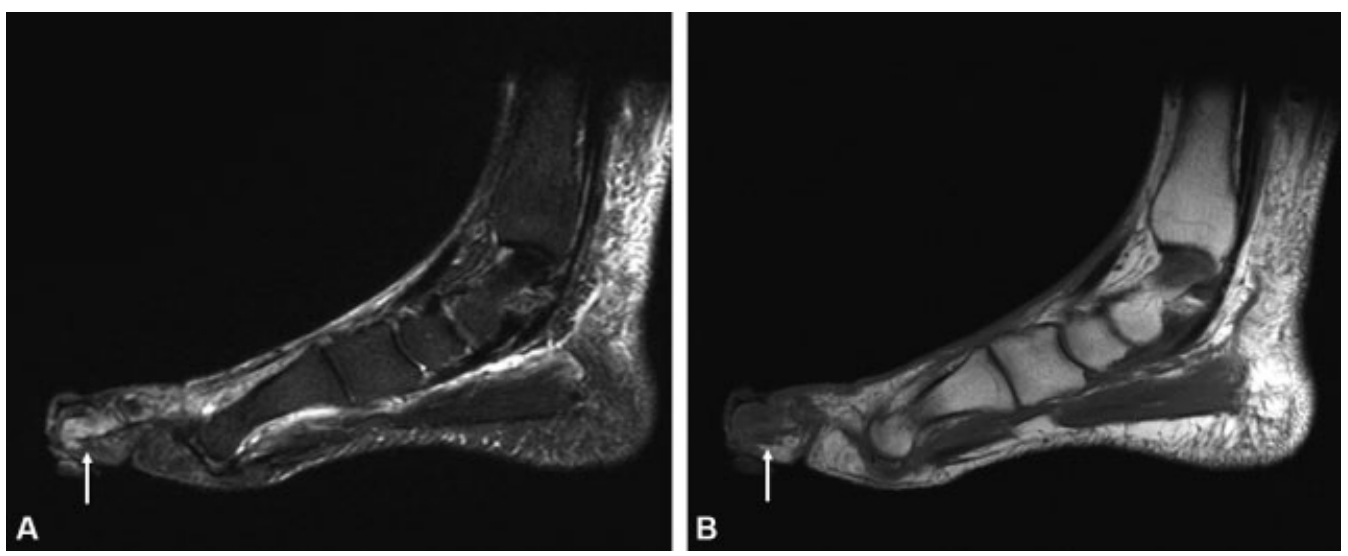

Fig. 4 RM pie izquierdo. Secuencias (A) STIR T2 sagital y (B) ponderada en T1 sagital. Edema óseo en falange distal del primer dedo, asociado a leve hiposeñal en secuencia ponderada en T1 (flechas), compatible con osteomielitis.

sitio de mayor prevalencia es el mediopié. Se caracteriza por cuatro etapas diferentes, que se asemejan a las fases de la enfermedad activa e inactiva: inflamación, fragmentación, coalescencia y consolidación. ${ }^{11,12}$

En la fase activa, el hueso se vuelve frágil debido a una osteopenia temporal, lo que conduce a fracturas, destrucción articular y colapso del arco longitudinal del pie. Durante la fase inactiva aparecen osteofitos prominentes y cuerpos libres, como consecuencia de una destrucción sustancial articular y ósea, seguida de proliferaciones óseas. La apariencia típica de la etapa final de un pie de Charcot es la deformidad "en mecedora." ${ }^{3,12,13}$

La $\mathrm{Rx}$ convencional ha sido tradicionalmente la técnica para establecer el diagnóstico, estadificar y controlar la enfermedad. Su principal ventaja es que permite evaluar la posición de los huesos entre sí y, en particular, bajo carga. ${ }^{13}$ En una fase temprana es posible no ver alteraciones radiográficas. Los cambios se harán más evidentes en etapas más avanzadas, pudiendo observar destrucción ósea y articular, seguido de luxaciones o subluxaciones de la articulación afectada, culminando con la deformidad "en mecedora," caracterizada por la pérdida del arco plantar, transfiriendo el soporte del pie al cuboides. ${ }^{11}$

Los clásicos hallazgos radiográficos en la neuroartropatía de Charcot se resumen en cinco conceptos (en inglés "the five D's"), que corresponden a densidad ósea anormal, derrame articular, fragmentación ósea, desorganización articular y luxaciones, siendo la más frecuente la tarso-metatarsiana (articulación de Lisfranc) (-Fig. 5). ${ }^{14}$

Inicialmente, la TC no aporta gran información con respecto a las ventajas de la RM. Sin embargo, su rendimiento aumenta en etapas posteriores, siendo útil para caracterizar mejor los hallazgos radiográficos. ${ }^{3}$

La RM es principalmente útil para establecer un diagnóstico precoz de la enfermedad y para monitorizar su actividad. Con respecto al protocolo de RM, es recomendable usar un gran campo de visión (FOV), ya que la enfermedad puede afectar todo el pie. En la etapa temprana, los signos observables son el edema de la médula ósea y tejidos blandos, el derrame articular y microfracturas (subcondrales). ${ }^{11-13}$ Es necesario usar una secuencia sensible a fluidos (por ejemplo, STIR), para evaluar los hallazgos mencionados. Otra secuencia fundamental es $\mathrm{T} 1$, que permite demostrar la anatomía y señal grasa de la médula ósea. ${ }^{13}$

En la etapa tardía es posible observar luxaciones articulares y fracturas corticales. Puede haber presencia de edema de médula ósea, según la actividad de la enfermedad. Especialmente en la articulación de Lisfranc, se pueden observar subluxaciones típicamente superior y lateral de los metatarsianos, con colapso completo del arco longitudinal. La cabeza del astrágalo suele inclinarse hacia la planta del pie y el hueso navicular se luxa hacia una posición media y superior, frecuentemente asociado a fracturas y fragmentación (-Fig. 6). En estados muy
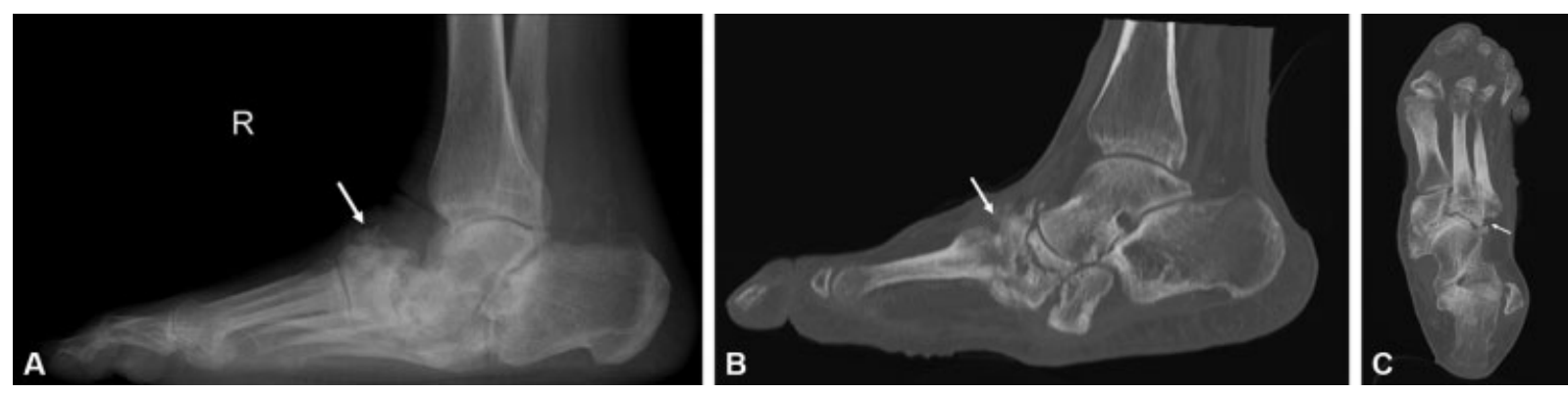

Fig. 5 (A) Rx de pie derecho en proyección lateral y TC (del mismo pie) en cortes (B) sagital y (C) axial. Manifestaciones avanzadas de neuroartropatía de Charcot con importante distorsión articular principalmente a nivel tarso-metatarsiano y en escafoides y cuboides, caracterizado por destrucción ósea, pérdida de la congruencia articular y proliferación ósea reactiva (flechas). 

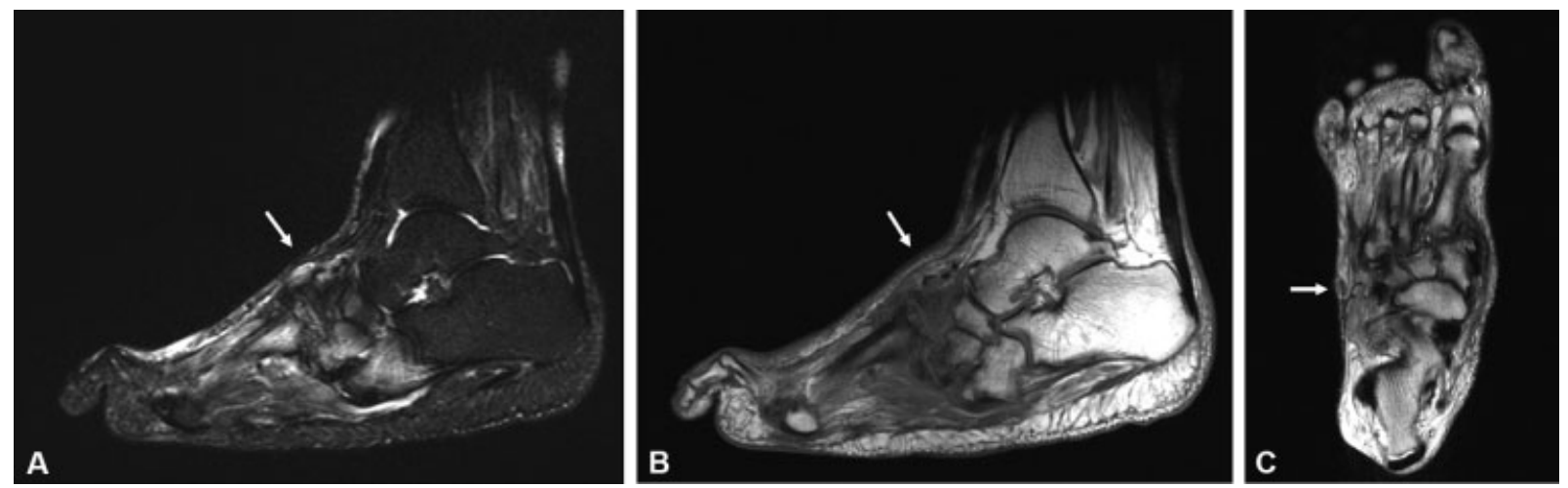

Fig. 6 RM de pie. Secuencias (A) STIR sagital, (B) ponderada en T1 sagital y (C) ponderada en T2 axial. Alteraciones en la articulación de Lisfranc consistentes con destrucción ósea, pérdida de la congruencia articular y artrosis secundaria de la articulación del mediopié. Además, se identifica hiposeñal en secuencia ponderada en T1 (B) e hiperseñal en STIR (A), consistente con edema óseo (flechas).

avanzados, es característica la presencia de esclerosis y proliferación ósea, cuerpos intra-articulares, quistes subcondrales, colecciones líquidas o trayectos fistulosos, esos últimos mejor visualizados en secuencias potenciadas en $\mathrm{T} 2$. $^{12,13}$

Debido a que el hueso cuboides se convierte en el más inferior del pie, este es más propenso a la formación de hiperqueratosis, ampollas y úlceras extensas, especialmente a este nivel. Ello puede conducir a infecciones de tejidos blandos y osteomielitis. En esos casos, resulta útil la aplicación de medio de contraste, indicación controversial en otros casos, por el riesgo intrínseco de insuficiencia renal que ese tipo de pacientes posee. ${ }^{3}$

\section{Osteomielitis}

La osteomielitis ocurre en el $90 \%$ a partir de una úlcera cutánea infectada. Las localizaciones más frecuentes son las cabezas de metatarsianos, falanges y calcáneo. Ante la sospecha clínica de infección, la Rx simple sigue siendo el procedimiento radiológico inicial, que ayuda a excluir otros procesos. Lamentablemente, los signos no aparecen hasta al menos dos semanas del comienzo de la infección, ya que requiere una pérdida del $40 \%$ al $70 \%$ de tejido óseo para ser visible, lo cual disminuye su sensibilidad y especificidad en un $66 \%$ y $60 \%$ respectivamente, pero sí puede ser útil clínicamente al ser inicialmente normal e ir observando cambios en los sucesivos controles radiográficos. Los signos que se pueden identificar son: disminución de la densidad ósea, periostitis, erosión y destrucción ósea, gas en los tejidos blandos, secuestros (hueso desvitalizado con aspecto radiodenso que se ha separado del hueso normal), involucro (crecimiento de tejido óseo nuevo fuera del hueso existente como resultado del desprendimiento del periostio) y cloacas (apertura en el involucro o la corteza a través de la cual se puede descargar tejido secuestrado) (-Figs. 7 y 8). ${ }^{15}$

Cuando se necesita un estudio avanzado, la RM es el examen de elección. En un meta-análisis, su sensibilidad para diagnosticar osteomielitis en el pie diabético fue del $90 \%$, mientras que la especificidad fue del $79 \%$. La principal ventaja de RM es su capacidad para identificar la extensión del área afectada. La forma más fácil de detectar la
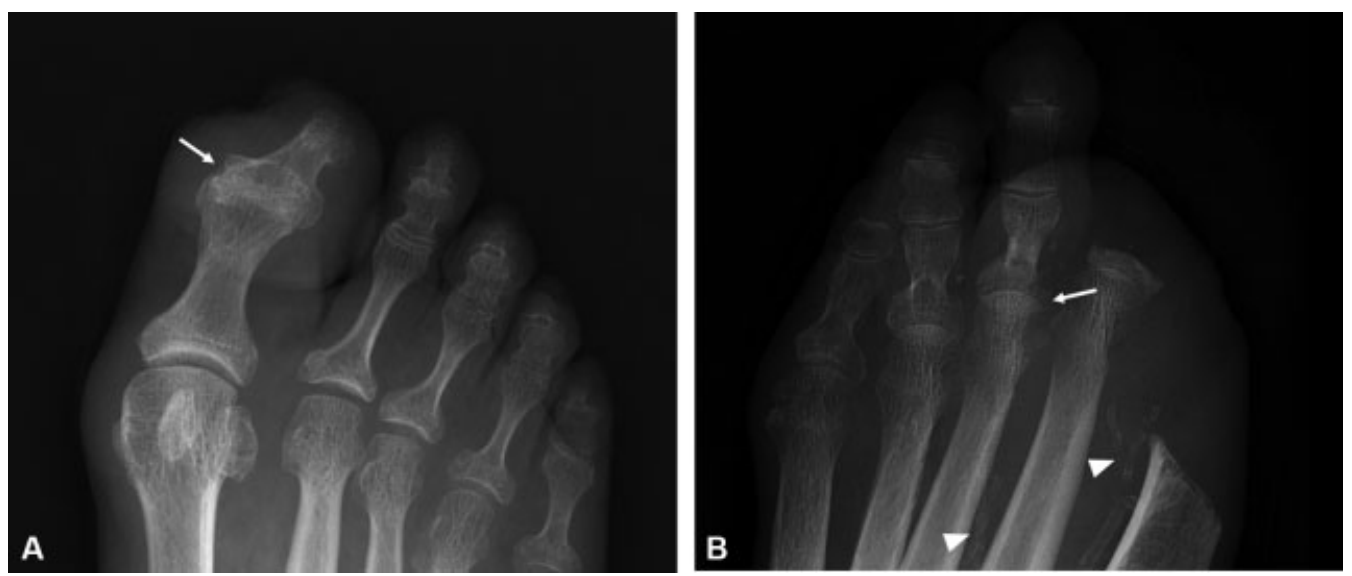

Fig. 7 Rx en proyección ántero-posterior de dos pacientes diferentes, de (A) pie derecho y (B) pie izquierdo. (A) Irregularidad y pérdida de la cortical focal en el aspecto medial y proximal de la falange distal del primer dedo, compatible con foco de osteomielitis inicial (flecha), que se asocia a aumento de densidad y volumen de las partes blandas adyacentes. (B) Osteomielitis avanzada en la base de la falange proximal y en el extremo distal del tercer metatarsiano (flecha). Además, se reconocen calcificaciones vasculares (puntas de flecha) y amputaciones en el primer y segundo dedos. 

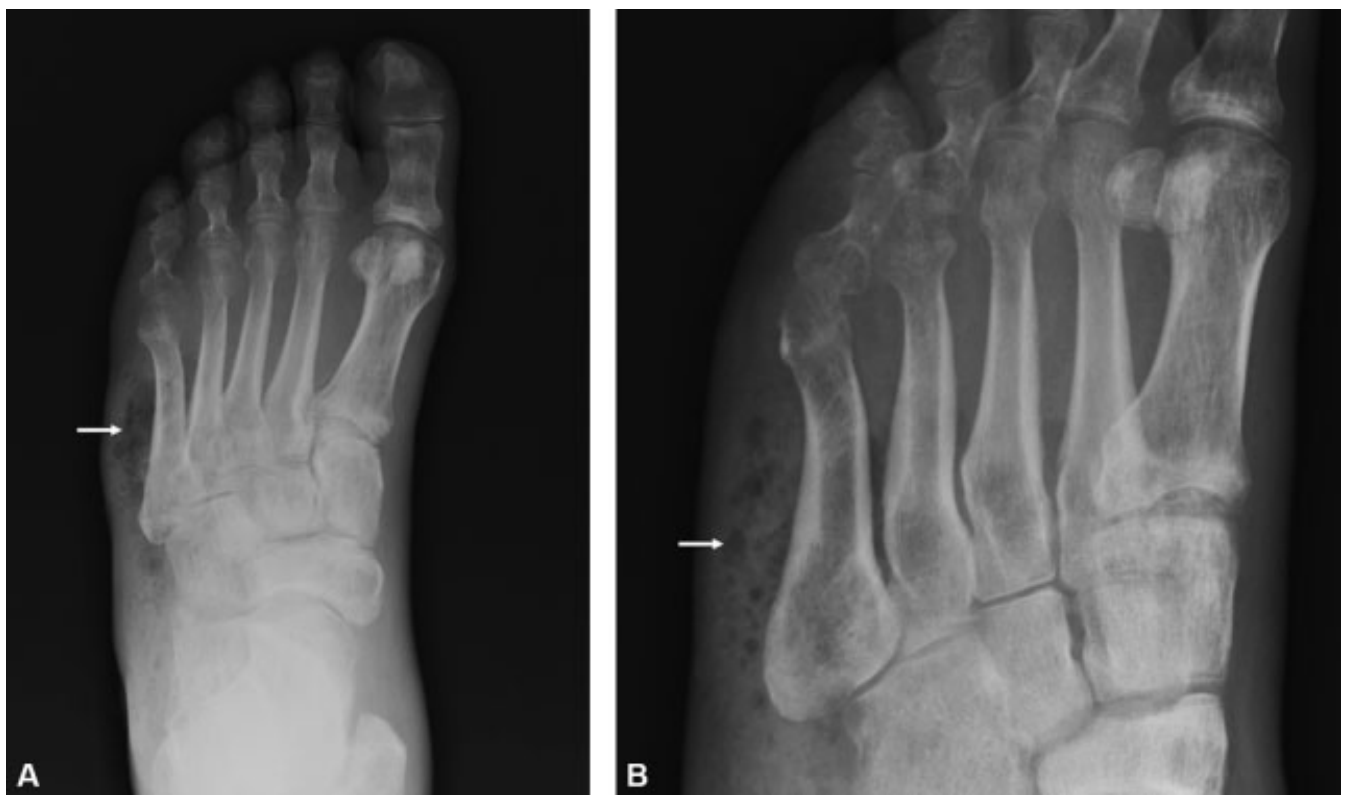

Fig. 8 Rx de pie izquierdo, proyecciones (A) antero-posterior y (B) oblicua. En ambas imágenes se observa gas en los tejidos blandos, en el contexto de celulitis asociado a osteomielitis (flechas).

osteomielitis es seguir el camino de la úlcera de la piel o el tracto sinusal hacia el hueso y evaluar la intensidad de la señal ósea. De esa manera, se pueden distinguir úlceras en la piel, trayectos fistulosos, abscesos adyacentes al hueso afectado, sinovitis, disrupción de la cortical, periostitis y característicamente alteraciones de señal de la médula ósea, con baja señal en secuencias ponderadas en T1, aumento de señal en secuencias ponderadas en T2 y STIR y realce con gadolinio (-Fig. 9). ${ }^{16}$

La osteomielitis no debe confundirse con la osteítis, que son los cambios reactivos de la médula secundaria a una infección vecina. En las imágenes ponderadas en T2, la osteítis aparece como médula hiperintensa, que es idéntica a la observada en la osteomielitis. Sin embargo, en las imágenes ponderadas en T1 no demuestra la señal baja que caracteriza a la osteomielitis. El realce de la médula ósea puede verse, pero no es confiable para discriminar entre las dos entidades. ${ }^{17}$

\section{Conclusión}

Una gran variedad de lesiones músculo-esqueléticas pueden ocurrir en el contexto del pie diabético, y las distintas modalidades imagenológicas contribuyen beneficiosamente a su caracterización.

Las lesiones óseas a menudo son más evidentes en las imágenes de radiología simple y TC, mientras que la RM aporta un gran detalle en la evaluación de partes blandas y de la osteomielitis. El uso de secuencias DWI y ADC, permite diferenciar las colecciones asépticas de las sépticas/absceso, en las que el valor ADC de esas últimas es notoriamente más bajo, a pesar de ser ambas hiperintensas en DWI. Lo anterior
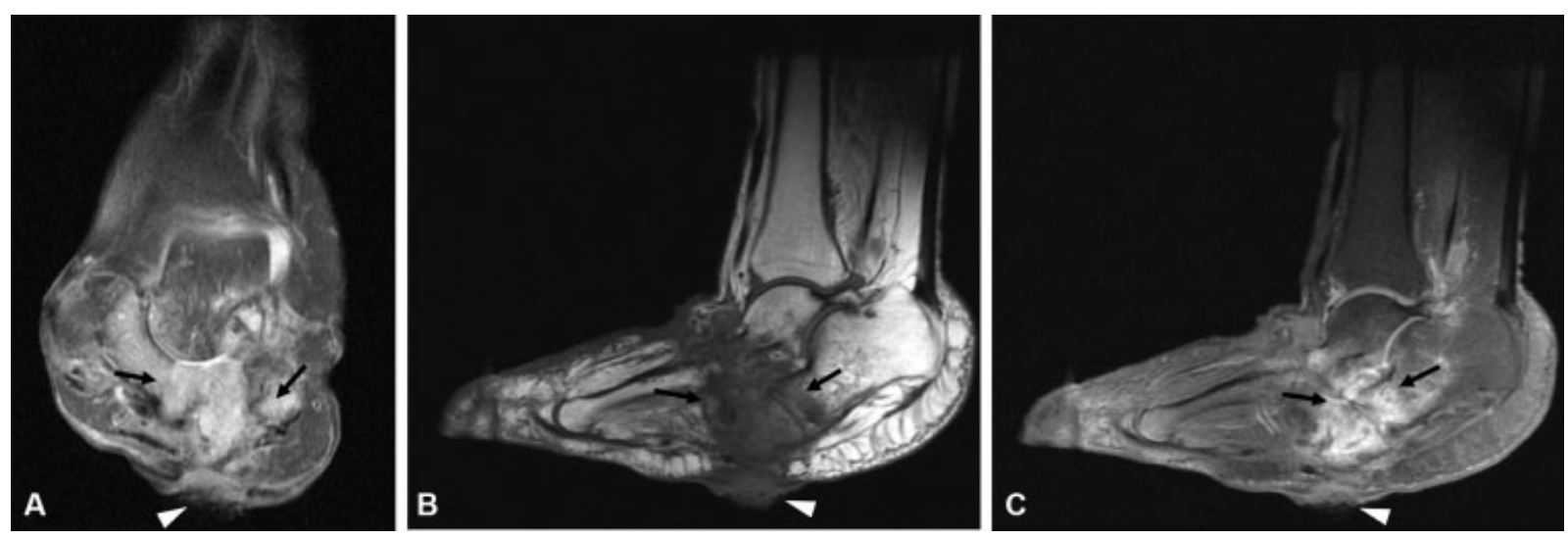

Fig. 9 RM de pie izquierdo. Secuencias (A) DP fat-sat coronal, (B) ponderada en T1 sagital y (C) ponderada en T1 fat-sat sagital con gadolinio. Neuroartropatía diabética avanzada en RM con importante compromiso del mediopié, asociado a úlcera plantar profunda (cabezas de flecha), que compromete hasta el plano óseo con irregularidad cortical y destrucción ósea asociada a edema inflamatorio principalmente del cuboides, navicular y extremo distal del calcáneo con características de osteomielitis (flechas negras). 
cobra especial importancia en el grupo de pacientes diabéticos, donde la concomitancia con patología renal es frecuente y el uso de contraste intravenoso puede ser un elemento a considerar por el riesgo de fibrosis sistémica nefrogénica.

El conocimiento de las variaciones de las características de la imagen, un enfoque sistemático y una correlación con datos clínicos, ayudarán a mejorar la precisión diagnóstica de las lesiones músculo-esqueléticas desarrolladas en esa entidad.

\section{Responsabilidades Éticas}

Protección de personas y animales. Los autores declaran que para esta investigación no se han realizado experimentos en seres humanos ni en animales.

Confidencialidad de los datos. Los autores declaran que han seguido los protocolos de su centro de trabajo sobre la publicación de datos de pacientes.

Derecho a la privacidad y consentimiento informado. Los autores declaran que en este artículo no aparecen datos de pacientes.

Conflicto de Intereses

Los autores declaran no tener ningún conflicto de intereses.

\section{Referencias}

1 Martín Noguerol T, Luna Alcalá A, Beltrán LS, Gómez Cabrera M, Broncano Cabrero J, Vilanova JC. Advanced MR imaging techniques for differentiation of neuropathic arthropathy and osteomyelitis in the diabetic foot. Radiographics. 2017;37(04):1161-1180

2 International Diabetes Federation. IDF Diabetes Atlas. 8th edition. BrusselsBelgium2017. Available at: http://www.diabetesatlas.org/
3 Baker JC, Demertzis JL, Rhodes NG, Wessell DE, Rubin DA. Diabetic musculoskeletal complications and their imaging mimics. Radiographics. 2012;32(07):1959-1974

4 Donovan A, Schweitzer ME. Use of MR imaging in diagnosing diabetes-related pedal osteomyelitis. Radiographics. 2010;30 (03):723-736

5 Moreno MJ, Vega ML, Martín A. Pie diabético. Hallazgos en la RM. Revista Internacional de Ciencias Podológicas. 2010;4(01):45-53

6 Morrison WB, Ledermann HP. Work-up of the diabetic foot. Radiol Clin North Am. 2002;40(05):1171-1192

7 Jelinek JS, Murphey MD, Aboulafia AJ, Dussault RG, Kaplan PA, Snearly WN. Muscle infarction in patients with diabetes mellitus: MR imaging findings. Radiology. 1999;211(01):241-247

8 Belsky DS, Teates CD, Hartman ML. Case report: diabetes mellitus as a predisposing factor in the development of pyomyositis. Am J Med Sci. 1994;308(04):251-254

9 Kamath S, Venkatanarasimha N, Walsh MA, Hughes PM. MRI appearance of muscle denervation. Skeletal Radiol. 2008;37 (05):397-404

10 Chatha DS, Cunningham PM, Schweitzer ME. MR imaging of the diabetic foot: diagnostic challenges. Radiol Clin North Am. 2005; 43(04):747-759, ix

11 Mautone M, Naidoo P. What the radiologist needs to know about Charcot foot. J Med Imaging Radiat Oncol. 2015;59(04):395-402

12 Ergen FB, Sanverdi SE, Oznur A. Charcot foot in diabetes and an update on imaging. Diabet Foot Ankle. 2013;4:4

13 Rosskopf AB, Loupatatzis C, Pfirrmann CWA, Böni T, Berli MC. The Charcot foot: a pictorial review. Insights Imaging. 2019;10(01):77

14 Schoots IG, Slim FJ, Busch-Westbroek TE, Maas M. Neuroosteoarthropathy of the foot-radiologist: friend or foe? Semin Musculoskelet Radiol. 2010;14(03):365-376

15 Shank CF, Feibel JB. Osteomyelitis in the diabetic foot: diagnosis and management. Foot Ankle Clin. 2006;11(04):775-789

16 Capriotti G, Chianelli M, Signore A. Nuclear medicine imaging of diabetic foot infection: results of meta-analysis. Nucl Med Commun. 2006;27(10):757-764

17 Low KTA, Peh WCG. Magnetic resonance imaging of diabetic foot complications. Singapore Med J. 2015;56(01):23-33, quiz 34 